\title{
Operando Local pH Measurement within Gas Diffusion Electrodes Performing Electrochemical Carbon Dioxide Reduction
}

Alex J. Welch, ${ }^{1,3}$ Aidan Q. Fenwick, ${ }^{2,3}$ Annette Böhme, ${ }^{1,3}$ Hsiang-Yun Chen, ${ }^{2}$ Ian Sullivan, ${ }^{3}$ Xueqian Li, ${ }^{1,3}$ Joseph S. Duchene, ${ }^{4}$ Chengxiang Xiang, ${ }^{3}$ and Harry A. Atwater ${ }^{1,3} *$

${ }^{1}$ Department of Applied Physics and Material Science, California Institute of Technology, Pasadena, CA 91125, USA

${ }^{2}$ Department of Chemistry, California Institute of Technology, Pasadena, CA 91125, USA

${ }^{3}$ Liquid Sunlight Alliance, California Institute of Technology, Pasadena, CA 91125, USA

${ }^{4}$ Department of Chemistry, University of Massachusetts Amherst, MA 01003, USA

\section{Corresponding Author:}

*E-mail: haa@caltech.edu 


\section{Methods}

Materials: Potassium carbonate (99.995\%, Sigma Aldrich), potassium hydroxide (6984-06, Macron Fine Chemicals), nitric acid (18 M EMD Millipore Corporation), Pt mesh (99.9\% purity and $.0726 \mathrm{~mm}$ diameter wires, Alfa Aesar), carbon paper (Sigracet 22BB, Fuel Cell Store), and 6,8dihydroxy-1,3-pyrenedisulfonic acid (DHPDS, Sigma Aldrich) were used without modification unless otherwise noted. The materials for electron beam deposition were ordered from Plasmaterials. The Copper target was $99.999 \%$ pure with 0.125 " diameter and 0.125 " long pellets from Alfa Aesar. All water used for experiments was deionized and filtered through a $0.22 \mu \mathrm{m}$ Millipak Express 40, serial number 0826.

Fabrication of Cu electrodes: An AMOD dual electron beam deposition system (System 02520, Angstrom Engineering) was used to fabricate all samples. $300 \mathrm{~nm}$ of $\mathrm{Cu}$ was deposited onto the microporous layer of the gas diffusion electrode (GDE) at a rate of $2 \AA / \mathrm{s}$. The substrate holder was rotating for all depositions. Over the course of the deposition the partial pressure of the chamber would rise from $\sim 10^{-7}$ torr to $\sim 10^{-6}$ torr and the temperature would rise from $20^{\circ} \mathrm{C}$ to $30{ }^{\circ} \mathrm{C}$ for a $300 \mathrm{~nm}$ thick sample. For samples that were used for confocal fluorescent microscopy, an aluminum foil shadow mask with $3 \mathrm{~mm}$ diameter holes was used. For electrodes used for product detection, no shadow mask was used. After deposition, the samples were first spray coated with a solution of carbon black and Nafion. The solution is one-part DI water and one-part isopropyl alcohol with $2.5 \mathrm{mg}$ of carbon black per $\mathrm{ml}$ of solution and $50 \mathrm{ml}$ of 5 weight \% Nafion per $\mathrm{ml}$ of solution. For both coatings the solution was sprayed from a distance of 3 inches for 1 second per square inch of electrode. After the samples were coated, they were dried under vacuum overnight.

\section{Scanning Electron Microscopy (SEM) characterization:}

The fabricated samples were imaged in a NOVA NanoSEM 450 with an acceleration voltage of $15 \mathrm{kV}$ and spot size of 3.

\section{Energy Dispersive X-ray Spectroscopy (EDS) characterization:}

The fabricated samples were imaged with an Oxford Instrument's Xmax $80 \mathrm{~mm}^{2}$ in a NOVA NanoSEM 450. The acceleration voltage was $15 \mathrm{keV}$ and the spot size was 5.

\section{Calibration of DHPDS ratiometric fluorescent dye:}

DHPDS was calibrated by collecting the fluorescence from two different wavelength excitations (458 $\mathrm{nm}$ and $488 \mathrm{~nm}$ ) for a range of $\mathrm{pH}$ solutions. The solutions were made by mixing $\mathrm{KOH}$, bicarbonate, water and standard buffer solutions. The $\mathrm{pH}$ of these solutions was measured by a Denver Instruments Ultra Basic $\mathrm{pH}$ meter and results were confirmed with color changing $\mathrm{pH}$ strips. The $\mathrm{pH}$ meter was calibrated with buffer solutions at $\mathrm{pH} 4, \mathrm{pH}$, and $\mathrm{pH} 10$ before every set of measurements. The solution was then placed under the microscope and the water immersion objective was immersed in it. The objective was then focused on a point in the middle of the solution. Three images were then taken here with sequential line by line excitation of $458 \mathrm{~nm}$ and $488 \mathrm{~nm}$. The fluorescence intensity signal was gathered from $515-700 \mathrm{~nm}$. The ratio of the fluorescence from these two excitations was then plotted vs. $\mathrm{pH}$ to generate Figure $\mathrm{S} 2 \mathrm{~b}$. The $\mathrm{pH}$ was measured again after the image was taken to make sure the $\mathrm{pH}$ reading is accurate. After acquiring all of the data, we fit the $\mathrm{pH}$ data to the function, $\mathrm{y}=-\mathrm{a} /(1+\exp (-\mathrm{b} *(\mathrm{x}-\mathrm{c})))+\mathrm{d}$. We found that coefficients to be $\mathrm{a}=-33.72, \mathrm{~b}=1.413, \mathrm{c}=8.083$, and $\mathrm{d}=5.571$ for a $95 \%$ confidence bounds. We therefore have an error of $0.3 \mathrm{pH}$ units.

\section{Electrocatalytic $\mathrm{CO}_{2}$ reduction reaction experiments for product analysis:}


An electrochemical cell made of polyether ether ketone (PEEK) was used to perform $\mathrm{CO}_{2}$ reduction reaction experiments. A volume of $20 \mathrm{~mL}$ of $100 \mathrm{mM} \mathrm{KHCO} 3$ was added to the catholyte bath and the anolyte bath. The electrolyte was then flowed by the cathode and anode separately at a rate of $6.3 \mathrm{ml} / \mathrm{min}$. The $\mathrm{Cu}$ GDE served as the working electrode with a $\mathrm{Ag} / \mathrm{AgCl}$ leakless reference electrode and a Pt mesh counter electrode. The cathode electrode and the anode are separated by an anion exchange membrane (AGC, Selemion AMV). $\mathrm{CO}_{2}$ saturated $100 \mathrm{mM} \mathrm{KHCO} 3$ (pH 6.8) was prepared by bubbling $\mathrm{CO}_{2}$ (Research grade from Airgas) into the electrolyte for 30 minutes prior to experiments. $\mathrm{CO}_{2}$ was flowed through the serpentine gas chamber at the back of the cathode at a rate of 10 standard cubic centimeters per minute (SCCM). The outflowing gas from the cell was sent back to the electrolyte bath in case there is any breakthrough of electrolyte through the GDE. From there, the gas was sent through a flow meter to check that the flow of $\mathrm{CO}_{2}$ in and out of the cell was the same, ensuring that it was thoroughly sealed against gas leaks. The outflowing gas was sent through a vapor trap to remove all water from the air before it was fed into a (SRI-8610) gas chromatograph.

All experiments were performed at room temperature with a Biologic VSP-300 potentiostat. All experiments were chronoamperometric, meaning that they were at constant voltage. All potentials were converted to the reversible hydrogen electrode (RHE) scale using the equation: $E$ vs. RHE $=E$ vs. $\mathrm{Ag} / \mathrm{AgCl}+0.197 \mathrm{~V}+0.059 \mathrm{~V} \mathrm{pH}^{-1} \times($ bulk solution $\mathrm{pH})$. Before each experiment, potentiostatic electrochemical impedance spectroscopy (PEIS) was performed to determine the solution resistance of the cell, which was typically between $10-50 \Omega$. The applied electrochemical potential was then compensated by $85 \%$ using iR compensation of the potentiostat. The electrochemical cell was dismounted and rinsed multiple times after each experiment with the same electrode and then stored in $10 \mathrm{wt} . \% \mathrm{HNO}_{3}$. Prior to each experiment, the cell was sonicated for $10 \mathrm{~min}$ in water at least four times.

\section{Electrocatalytic $\mathrm{CO}_{2}$ reduction reaction experiments for $\mathrm{pH}$ imaging:}

An electrochemical cell made of polyether ether ketone (PEEK) was used to perform $\mathrm{CO}_{2}$ reduction reaction experiments (Figure S1). A volume of $40 \mathrm{~mL}$ of $100 \mathrm{mM} \mathrm{KHCO}$ and $100 \mu \mathrm{M}$ DHPDS was added to the electrolyte bath. The electrolyte was then flowed through the cell at a rate of $6.3 \mathrm{ml} / \mathrm{min}$ by a Masterflex 77120-62 pump. $\mathrm{CO}_{2}$ flowed through the gas chamber at the back of the cathode at a rate of $10 \mathrm{SCCM}$. The $\mathrm{Cu}$ GDE served as the working electrode with a $\mathrm{Ag} / \mathrm{AgCl}$ leakless reference electrode and a Pt mesh counter electrode. $\mathrm{CO}_{2}$ saturated $100 \mathrm{mM} \mathrm{KHCO}$ ( $\mathrm{pH}$ 6.8) was prepared by bubbling $\mathrm{CO}_{2}$ (Research grade from Airgas) into the electrolyte for 30 min prior to experiments. The outflowing gas was sent back to the electrolyte bath in case there is any breakthrough of liquid through the GDE.

The objective (WN Achroplan 63x water immersion objective with a numerical aperture of 0.9) of the LSM 710 microscope is then lowered into the electrolyte and focused at the surface of the electrode. The power of the Argon laser is set to $100 \%$ power for $458 \mathrm{~nm}$ and $20 \%$ power for $488 \mathrm{~nm}$, and the gain for each channel is 800 . The intensity of the fluorescence is collected from $515 \mathrm{~nm}$ to 705 $\mathrm{nm}$. To create an image, the $458 \mathrm{~nm}$ laser scans one line, then the same line is scanned by the $488 \mathrm{~nm}$ laser. The fluorescence from each excitation is stored separately and this process is repeated to form a complete image. The data is then post processed using the calibration curve to determine the $\mathrm{pH}$. A ' $\mathrm{z}$ stack' of images is taken to create a series of images at the same location but at different heights above the electrode. When the electrode was passing current, the electrode was first allowed to stabilize for 15 minutes (until the working electrode potential was constant) before a set of images was taken.

All experiments were performed at room temperature with a Biologic SP-200 potentiostat. All electrolysis experiments were performed under galvanostatic conditions, meaning that they were at constant current. This was done so that flux of ions would be constant between electrodes. The working electrode potential was measured and is plotted in Figure S2. All potentials were converted to the 
reversible hydrogen electrode (RHE) scale using the equation: $E$ vs. $\mathrm{RHE}=E \mathrm{vs} . \mathrm{Ag} / \mathrm{AgCl}+0.197 \mathrm{~V}+$ $0.059 \mathrm{~V} \mathrm{pH}^{-1} \times($ bulk solution $\mathrm{pH})$. Before each experiment, potentiostatic electrochemical impedance spectroscopy (PEIS) was performed to determine the solution resistance of the cell, which was typically between $5-30 \Omega$. The applied electrochemical potential was then compensated by $85 \%$ using iR compensation of the potentiostat. The electrochemical cell was dismounted and rinsed multiple times after each experiment with the same electrode and then stored in $10 \mathrm{wt} \% \mathrm{HNO}_{3}$. Before using the cell for the next experiment, it was sonicated for $10 \mathrm{~min}$ in water at least 4 times.

\section{Choice of electrochemical cell:}

Two different electrochemical cells were used for the two experiments. The confocal microscope cell had specific design requirements, so that it would be compatible with the microscope that are not usually required of electrochemical cells. The main constraint is that the working distance of the objective is $1.7 \mathrm{~mm}$. This necessitated the removal of the membrane, so that the objective could be placed close to the cathode. Additionally, this required that the cell be rotated $90^{\circ}$ relative to a typical cell. Since the objective is being submerged in the electrolyte this means that the electrolyte is open to atmosphere and not sealed. The fact that the membrane is removed and the electrolyte is open to air makes it impossible to perform gas chromatography (GC) experiments with it. First, since the cell is not sealed, not all of the products can be captured and sent to the GC. Therefore, it is not possible to obtain an accurate Faradaic efficiency. Also since there is no membrane the anode can oxidize liquid products that are formed which also will make it impossible to get an accurate Faradaic efficiency.

Due to these considerations we opted to use a standard electrochemical cell for the GC experiments, one that has a membrane and is sealed. The change in electrochemical cell caused a significant change in current density. To make the results as relevant as possible we used the same potentials in both systems because similar potentials should produce similar products. Everything besides the electrochemical cell was kept the same between experiment - catalyst, electrolyte, $\mathrm{CO}_{2}$ flow rate, reference electrode, etc.

\section{COMSOL pH model:}

Simulations were performed with a stationary COMSOL Multiphysics 5.5 model with a combination of the Laminar Flow Module and the Transport of Diluted Species Module. To estimate the appropriate flow velocity close to the electrode surface, a three-dimensional COMSOL model with the Laminar Flow Module simulating the electrolyte flow in the electrochemical cell and around the immersion objective used for experiments was set up, see Fig. S16. The velocity at the inlet of the cell was experimentally determined to be $1.3 \mathrm{~mm} / \mathrm{s}$. As expected, the flow velocity underneath the objective is found to be much lower than around it. The average flow velocity $30 \mu \mathrm{m}$ above the electrode surface was determined to be $0.14 \mu \mathrm{m} / \mathrm{s}$. This value was used as an input for the two-dimensional model of $\mathrm{pH}$ around a trench.

The geometry of the two-dimensional model of the $\mathrm{pH}$ is depicted in Fig $5 \mathrm{~d}$. At the inlet (left), we assume a flow velocity of $0.14 \mu \mathrm{m} / \mathrm{s}$, at the outlet (right) a zero pressure condition is applied. On the electrode surface as well as on the trench walls and at the bottom of the trench we apply no-slip boundary conditions. Both convection and diffusion are taken into consideration for the transport properties. The inputs here are the velocity field calculated with the laminar flow module and the diffusion coefficients of all species (see Table S1). We assume a boundary layer thickness of $60 \mu \mathrm{m}$ where we apply concentration boundary conditions as expected for a $\mathrm{CO}_{2}$-saturated $100 \mathrm{mM} \mathrm{KHCO} 3$ electrolyte in equilibrium (see Table S1). The same concentrations are used as inflow concentrations at the inlet.

On the surface of the electrode as well as at the bottom and the side wall of the trench we assume a CO2 flux of $1 \frac{\mu \mathrm{mol}}{\mathrm{cm}^{2} \cdot \mathrm{s}}$. This value was determined experimentally by measuring the difference in the 
$\mathrm{CO}_{2}$ flow rate with a flow meter before and after passing the GDE in the electrochemical cell. Note that this method only provides an estimate as the $\mathrm{CO}_{2}$ flux though the GDE is not homogeneous.

Also on the electrode surface, the trench bottom and walls we assume that there is catalytic activity. The charge-transfer reactions considered on these walls are

$$
\begin{gathered}
\mathrm{CO}_{2}(\mathrm{aq})+\mathrm{H}_{2} \mathrm{O}+2 \mathrm{e}^{-} \rightarrow \mathrm{CO}+2 \mathrm{OH}^{-} \\
2 \mathrm{H}^{+}+2 \mathrm{e}^{-} \rightarrow \mathrm{H}_{2} \\
2 \mathrm{H}_{2} \mathrm{O}+2 \mathrm{e}^{-} \rightarrow \mathrm{H}_{2}+2 \mathrm{OH}^{-}
\end{gathered}
$$

The source terms are determined with

$$
R_{n}=-\sum \frac{s_{j} \cdot J \cdot F E_{n}}{n_{j} \cdot F}
$$

with $s_{j}$ the stoichiometric coefficient of equation $\mathrm{j}$, J the current density, $F E_{n}$ the Faradaic efficiency of species $n$ determined experimentally (see Fig 2, the Faradaic efficiency for CO is assumed to be the sum of the Faradaic Efficiency of all carbon products), $n_{j}$ the number of transferred electrons and F Faraday's constant.

Furthermore, bulk carbonate reactions are assumed to take place in the whole electrolyte body:

$$
\begin{gathered}
\mathrm{CO}_{2}(\mathrm{aq})+\mathrm{H}_{2} \mathrm{O} \rightarrow \mathrm{H}^{+}+\mathrm{HCO}_{3}{ }^{-} \\
\mathrm{HCO}_{3}^{-} \rightarrow \mathrm{H}^{+}+\mathrm{CO}_{3}{ }^{2-} \\
\mathrm{CO}_{2}(\mathrm{aq})+\mathrm{OH}^{-} \rightarrow \mathrm{HCO}_{3}^{-} \\
\mathrm{HCO}_{3}^{-}+\mathrm{OH}^{-} \rightarrow \mathrm{H}_{2} \mathrm{O}^{-} \mathrm{CO}_{3}{ }^{2-} \\
\mathrm{H}_{2} \mathrm{O} \rightarrow \mathrm{H}^{+}+\mathrm{OH}^{-}
\end{gathered}
$$

The source terms are calculated with

$$
R_{n}=\sum_{j} s_{j} \cdot\left(k_{j} \prod_{s_{j}<0} c_{n}-k_{-j} \prod_{s_{j}>0} c_{n}\right)
$$

where $s_{j}$ is the stoichiometric coefficient of reaction $\mathrm{j}, k_{j}$ the forward rate constant, $k_{-j}$ the reverse reaction rate constant, $k_{-j}=\frac{k_{j}}{K_{j}}$ with the equilibrium constant $K_{j}$ (see Table 1). $c_{n}$ is the concentration of species n. 
Table S1: Model Parameters

\section{Diffusion Coefficients}

(Weng et al, Phys. Chem. Chem. Phys., 2018, 20, 16973-16984)

\begin{tabular}{|c|c|}
\hline Species & Value \\
\hline $\mathrm{K}^{+}$ & $1.957 \cdot 10^{-5} \frac{\mathrm{cm}^{2}}{\mathrm{~s}}$ \\
\hline $\mathrm{H}^{+}$ & $9.311 \cdot 10^{-5} \frac{\mathrm{cm}^{2}}{\mathrm{~s}}$ \\
\hline $\mathrm{OH}^{-}$ & $5.293 \cdot 10^{-5} \frac{\mathrm{cm}^{2}}{\mathrm{~s}}$ \\
\hline $\mathrm{CO}_{2}$ & $1.91 \cdot 10^{-5} \frac{\mathrm{cm}^{2}}{\mathrm{~s}}$ \\
\hline $\mathrm{HCO}_{3}{ }^{-}$ & $1.185 \cdot 10^{-5} \frac{\mathrm{cm}^{2}}{\mathrm{~s}}$ \\
\hline $\mathrm{CO}_{3}{ }^{2-}$ & $0.91 \cdot 10^{-5} \frac{\mathrm{cm}^{2}}{\mathrm{~s}}$ \\
\hline
\end{tabular}

\begin{tabular}{|l|l|}
\hline \multicolumn{2}{|c|}{ Equilibrium Concentrations } \\
\hline Species & $100 \frac{\mathrm{mol}}{\mathrm{m}^{3}}$ \\
\hline $\mathrm{K}^{+}$ & $1.58 \cdot 10^{-4} \frac{\mathrm{mol}}{\mathrm{m}^{3}}$ \\
\hline $\mathrm{H}^{+}$ & $6.31 \cdot 10^{-5} \frac{\mathrm{mol}}{\mathrm{m}^{3}}$ \\
\hline $\mathrm{OH}^{-}$ & $37.13 \frac{\mathrm{mol}}{\mathrm{m}^{3}}$ \\
\hline $\mathrm{CO}_{2}$ & $99.94 \frac{\mathrm{mol}^{3}}{\mathrm{~m}^{3}}$ \\
\hline $\mathrm{HCO}_{3}^{-}$ & $3.02 \cdot 10^{-2} \frac{\mathrm{mol}}{\mathrm{m}^{3}}$ \\
\hline $\mathrm{CO}_{3}{ }^{--}$ &
\end{tabular}

Forward Rate Constants

(Schulz et al, Mar. Chem., 2006,100,53-65)

\begin{tabular}{|l|l|}
\hline $\mathrm{k}_{1}$ & $3.71 \cdot 10^{-2} \frac{1}{\mathrm{~s}}$ \\
\hline $\mathrm{k}_{2}$ & $59.44 \frac{1}{\mathrm{~s}}$ \\
\hline $\mathrm{k}_{3}$ & $2.23 \cdot 10^{3} \frac{\mathrm{L}}{\mathrm{mol} \cdot \mathrm{s}}$ \\
\hline $\mathrm{k}_{4}$ & $6 \cdot 10^{9} \frac{\mathrm{L}}{\mathrm{mol} \cdot \mathrm{s}}$ \\
\hline
\end{tabular}




\begin{tabular}{|c|l|}
\hline $\mathrm{k}_{\mathrm{w}}$ & $1.4 \cdot 10^{-3} \frac{\mathrm{mol}}{\mathrm{L} \cdot \mathrm{s}}$ \\
\hline \multicolumn{2}{|c|}{ Equilibrium Constants } \\
(Schulz et al, Mar. Chem., 2006,100,53-65) \\
\hline $\mathrm{K}_{1}$ & $10^{-6.37} \frac{\mathrm{mol}}{\mathrm{L}}$ \\
\hline $\mathrm{K}_{2}$ & $10^{-10.32} \frac{\mathrm{mol}}{\mathrm{L}}$ \\
\hline $\mathrm{K}_{3}$ & $\frac{K_{1}}{K_{w}}$ \\
\hline $\mathrm{K}_{4}$ & $\frac{K_{2}}{K_{w}}$ \\
\hline $\mathrm{K}_{\mathrm{w}}$ & $10^{-14} \frac{\mathrm{mol}^{2}}{\mathrm{~L}^{2}}$ \\
\hline
\end{tabular}


a)

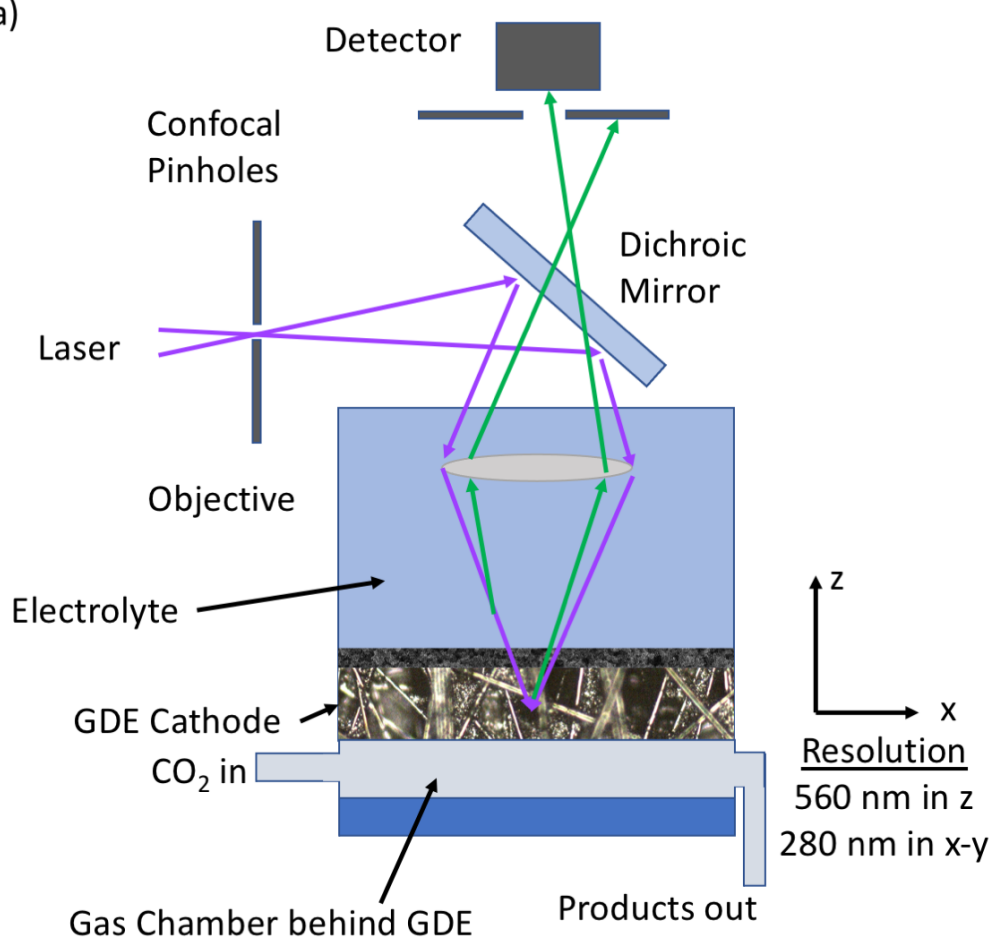

b)

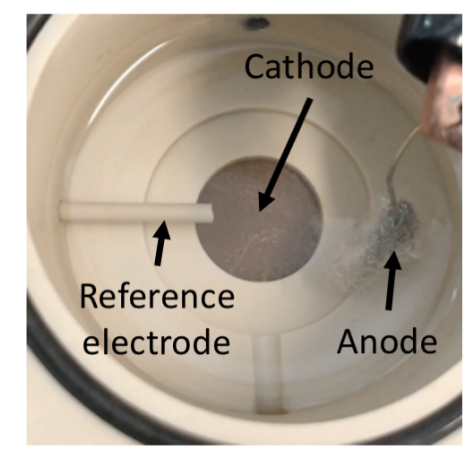

c)

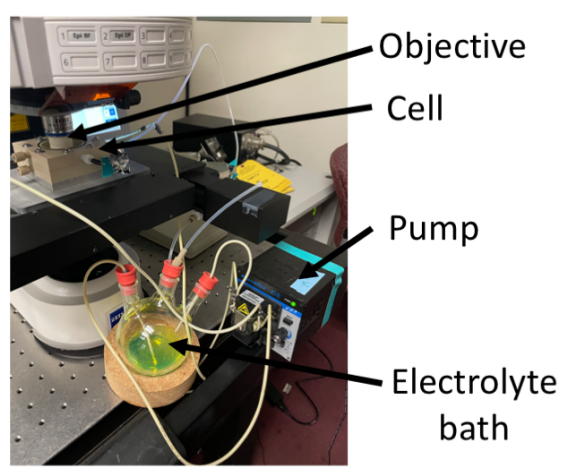

Figure S1: (a) shows a schematic of the electrochemical cell used for imaging the $\mathrm{pH}$ via confocal fluorescent microscopy. The bottom plate is the gas chamber and the top plate holds the electrolyte. This setup has no membrane and the electrolyte is constantly being flowed across the active catalyst layer. (b) shows a top-down photo of the electrochemical cell without the microscope objective. (c) shows a photo of the entire experimental setup with the objective in the cell, the electrolyte bath, and the pump to circulate the electrolyte through the electrochemical cell. 

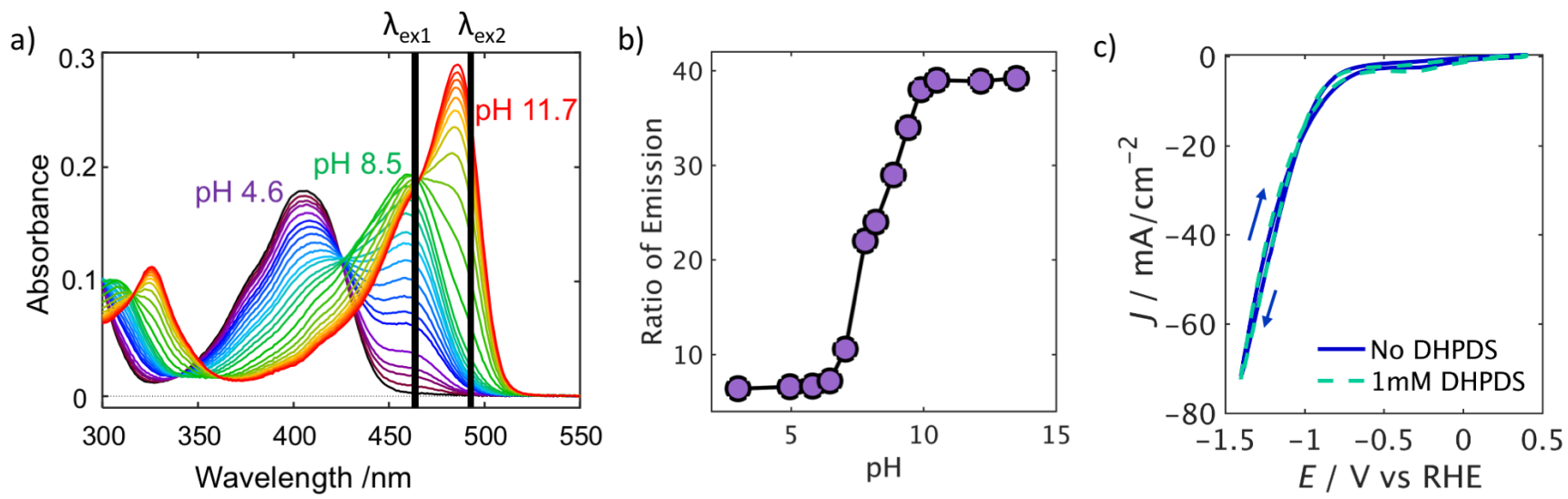

Figure S2: Characterization of the pH-sensitive DHPDS fluorescent dye. (a) shows the absorbance of DHPDS for different $\mathrm{pH}$ solutions. vertical black lines denote the two different excitation wavelengths $\left(\lambda_{\mathrm{ex} 1}=458 \mathrm{~nm}\right)$ and $\left(\lambda_{\mathrm{ex} 2}=458 \mathrm{~nm}\right)$ used for the study. (b) shows the ratio of fluorescence emission from a $458 \mathrm{~nm}$ and $488 \mathrm{~nm}$ excitation wavelength as a function of solution $\mathrm{pH}$. After acquiring all of the data, we fit the $\mathrm{pH}$ data to the function, $\mathrm{y}=-\mathrm{a} /\left(1+\exp \left(-\mathrm{b}^{*}(\mathrm{x}-\mathrm{c})\right)\right)+\mathrm{d}$. We found the coefficients to be $\mathrm{a}$ $=-33.72, \mathrm{~b}=1.413, \mathrm{c}=8.083$, and $\mathrm{d}=5.571$ for $95 \%$ confidence bounds. We therefore have an error of $0.3 \mathrm{pH}$ units. (c) shows the current (J) vs applied electrode potential (E) for a $\mathrm{CO}_{2}$ reduction electrode with (dashed line) and without (solid line) DHPDS dye in the electrolyte. 
a)

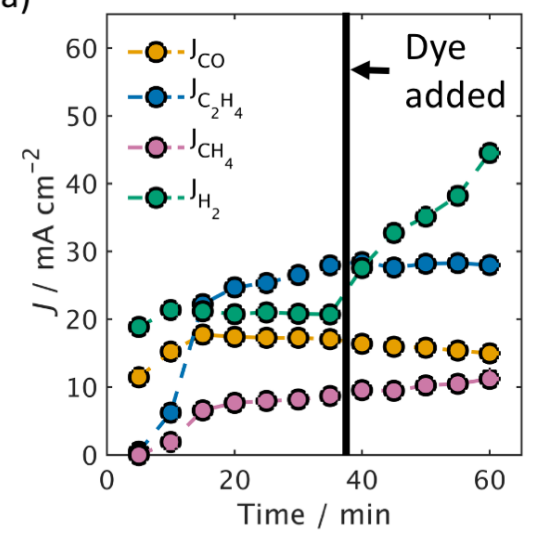

b)

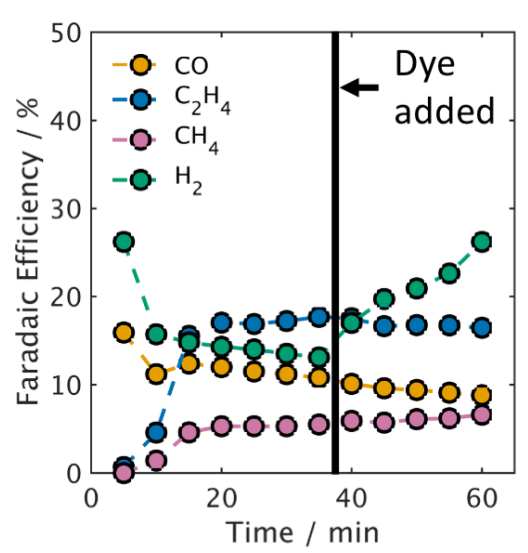

c)

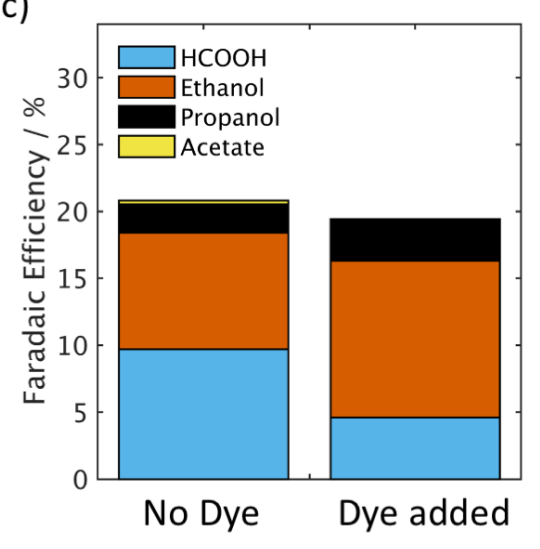

Figure S3: Characterization of how the $\mathrm{pH}$-sensitive DHPDS fluorescent dye affects the activity and selectivity of the copper GDE. (a) shows the current density $(\mathrm{J})$ vs time before the dye is added (0 to 34 minutes) and after the dye is added to the electrolyte at 35 minutes. The partial current density for HER increases but the $\mathrm{CO}_{2}$ reduction partial current densities remain stable. (b) shows the Faradaic efficiency for gas products vs time. The dye is added to the electrolyte at 35 minutes. The Faradaic efficiency for HER increases but the $\mathrm{CO}_{2}$ reduction Faradaic efficiency remains stable. (c) shows the Faradaic efficiency for liquid products before and after the dye was added. The Faradaic efficiency for the $\mathrm{CO}_{2}$ reduction reactions remain similar before and after the addition of the dye, albeit with slight increase in ethanol (orange) and decrease in formic acid (blue). 

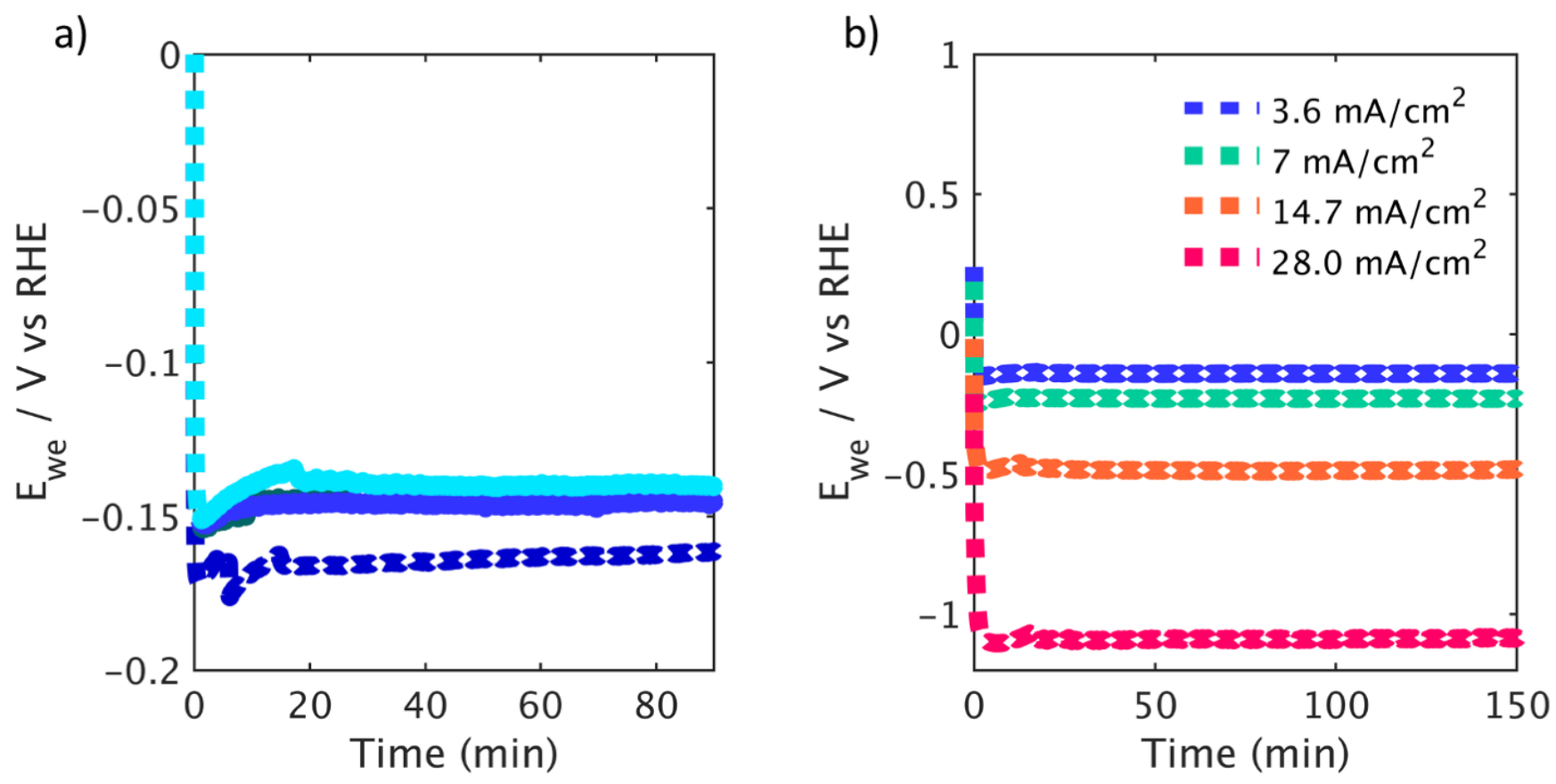

Figure S4: Stability of the $\mathrm{Cu}$ GDE working electrode potential $\left(\mathrm{E}_{\mathrm{we}}\right)$ over time. (a) shows four different electrochemical tests where the current density is set to $-3.4 \mathrm{~mA} / \mathrm{cm}^{2}$. From this we can see that there are only very small changes in potential of the working electrode between tests. (b) shows electrochemical tests with varying current density. We note that the potential of the working electrode is very stable after the first 5 minutes indicating that electrode is stable throughout the run. 

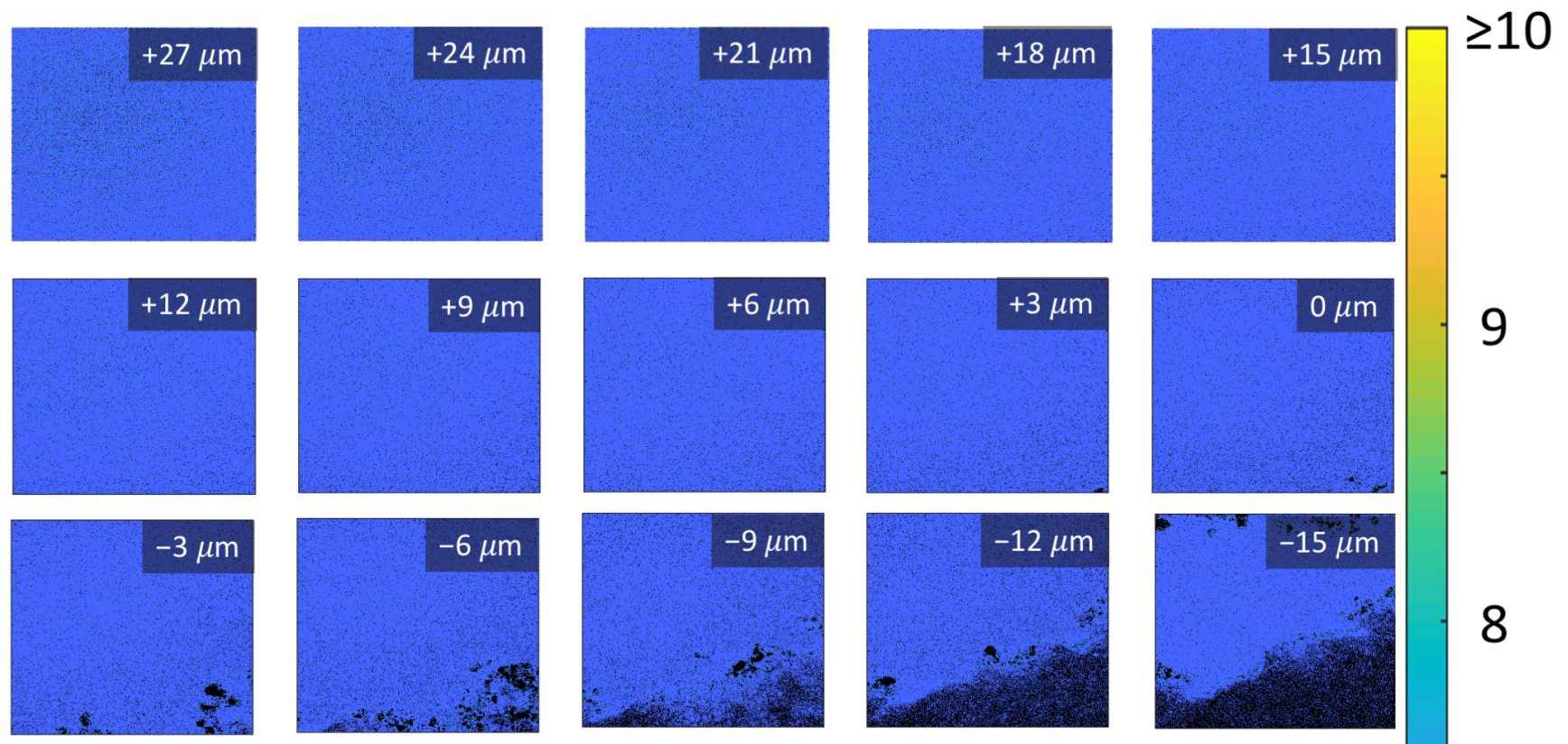

9
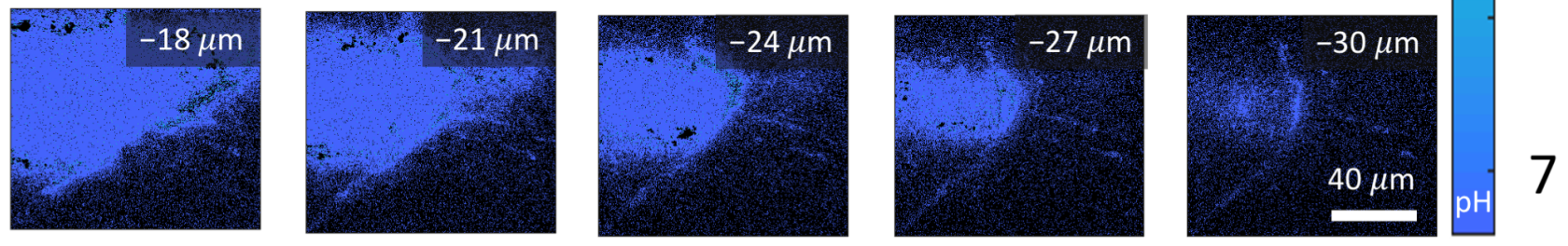

Figure S5: $\mathrm{pH}$ maps at the same location in $\mathrm{x}-\mathrm{y}$ on the electrode at different heights above the electrode surface under open-circuit conditions $\left(0 \mathrm{~mA} / \mathrm{cm}^{2}\right)$. The map at the top left is at $30 \mu \mathrm{m}$ above the surface of the electrode. The map immediately to the right (top row second column from the left) is $27 \mu \mathrm{m}$ above the surface of the electrode. Each map is $3 \mu \mathrm{m}$ below the previous one starting from top left and moving to bottom right row by row. The bottom right map is $30 \mu \mathrm{m}$ below the electrode surface. The $\mathrm{pH}$ scale and scale bar at the right apply to all images. 

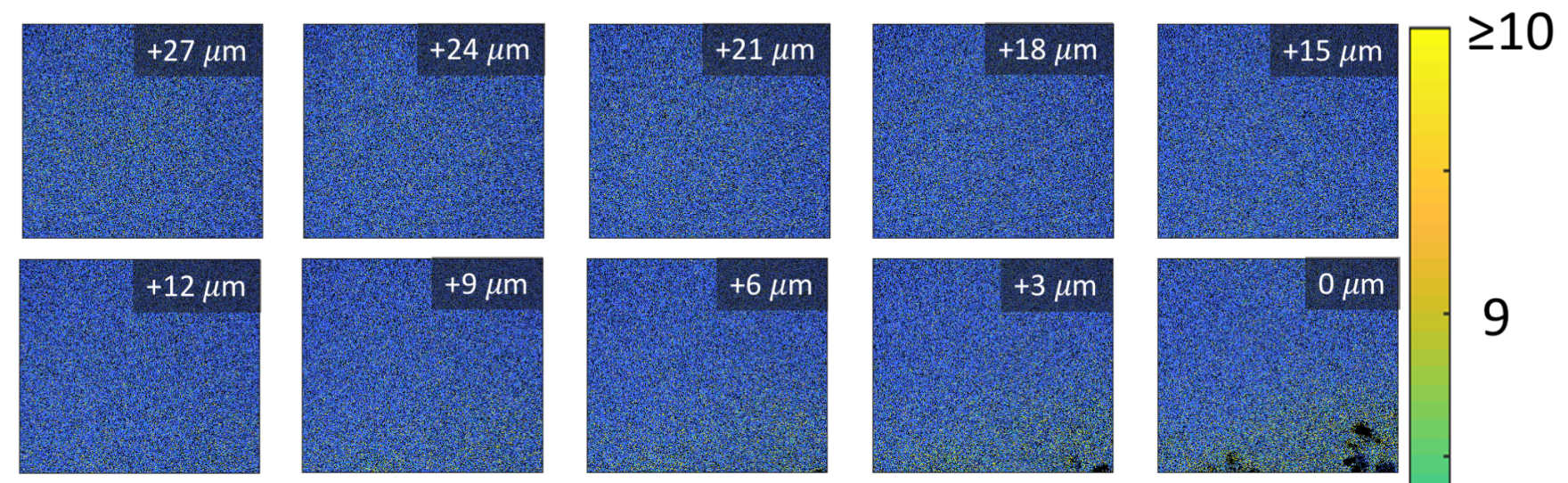

9
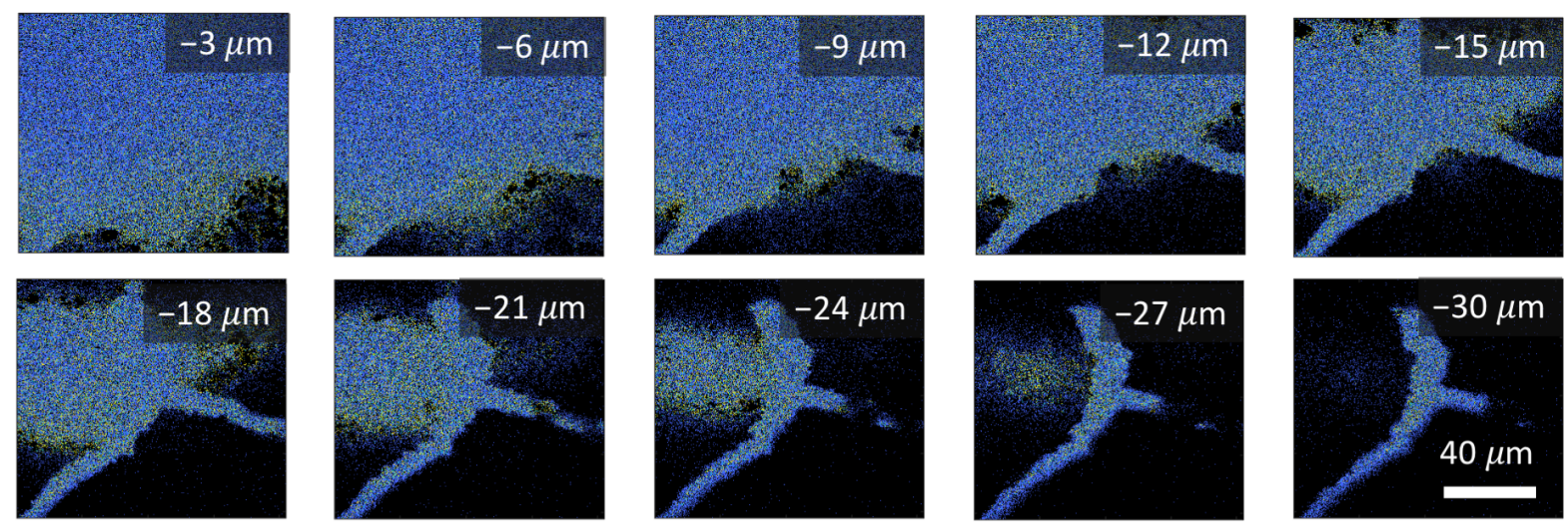

8

Figure S6: $\mathrm{pH}$ maps at the same location in $\mathrm{x}-\mathrm{y}$ on the electrode at different heights above the electrode surface at $-1.6 \mathrm{~mA} / \mathrm{cm}^{2}$. The map at the top left is at $30 \mu \mathrm{m}$ above the surface of the electrode. The map immediately to the right (top row second column from the left) is $27 \mu \mathrm{m}$ above the surface of the electrode. Each map is $3 \mu \mathrm{m}$ below the previous one starting from top left and moving to bottom right row by row. The bottom right map is $30 \mu \mathrm{m}$ below the electrode surface. The $\mathrm{pH}$ scale and scale bar at the right apply to all images. 

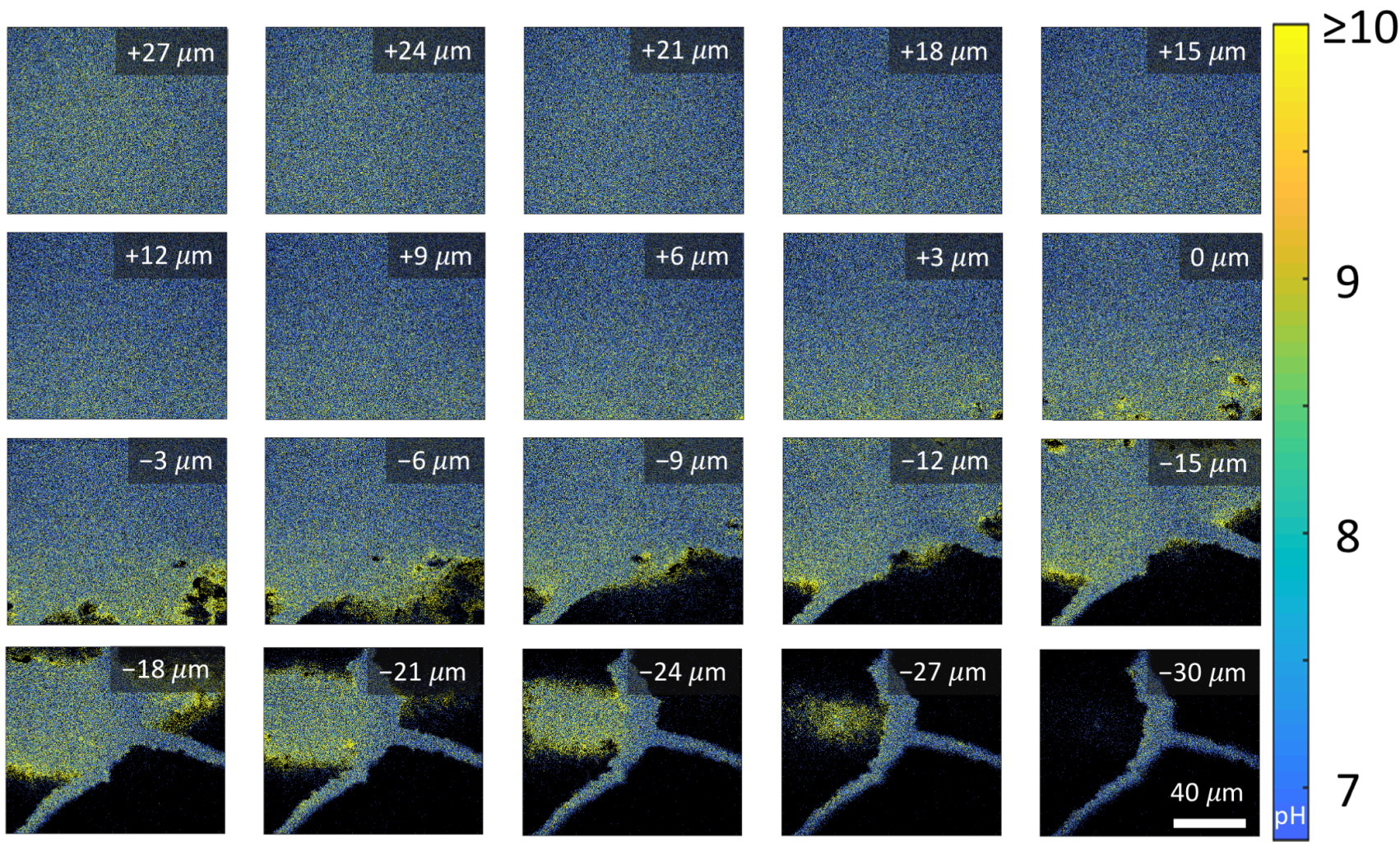

9
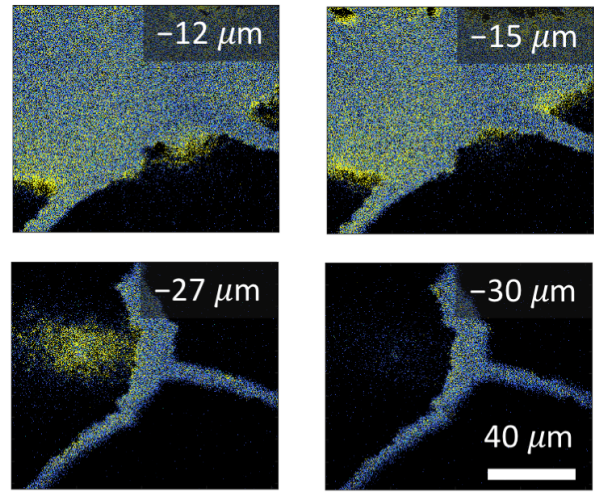

8

Figure S7: $\mathrm{pH}$ maps at the same location in $\mathrm{x}-\mathrm{y}$ on the electrode at different heights above the electrode surface at $-3.4 \mathrm{~mA} / \mathrm{cm}^{2}$. The map at the top left is at $30 \mu \mathrm{m}$ above the surface of the electrode. The map immediately to the right (top row second column from the left) is $27 \mu \mathrm{m}$ above the surface of the electrode. Each map is $3 \mu \mathrm{m}$ below the previous one starting from top left and moving to bottom right row by row. The bottom right map is $30 \mu \mathrm{m}$ below the electrode surface. The $\mathrm{pH}$ scale and scale bar at the right apply to all images. 

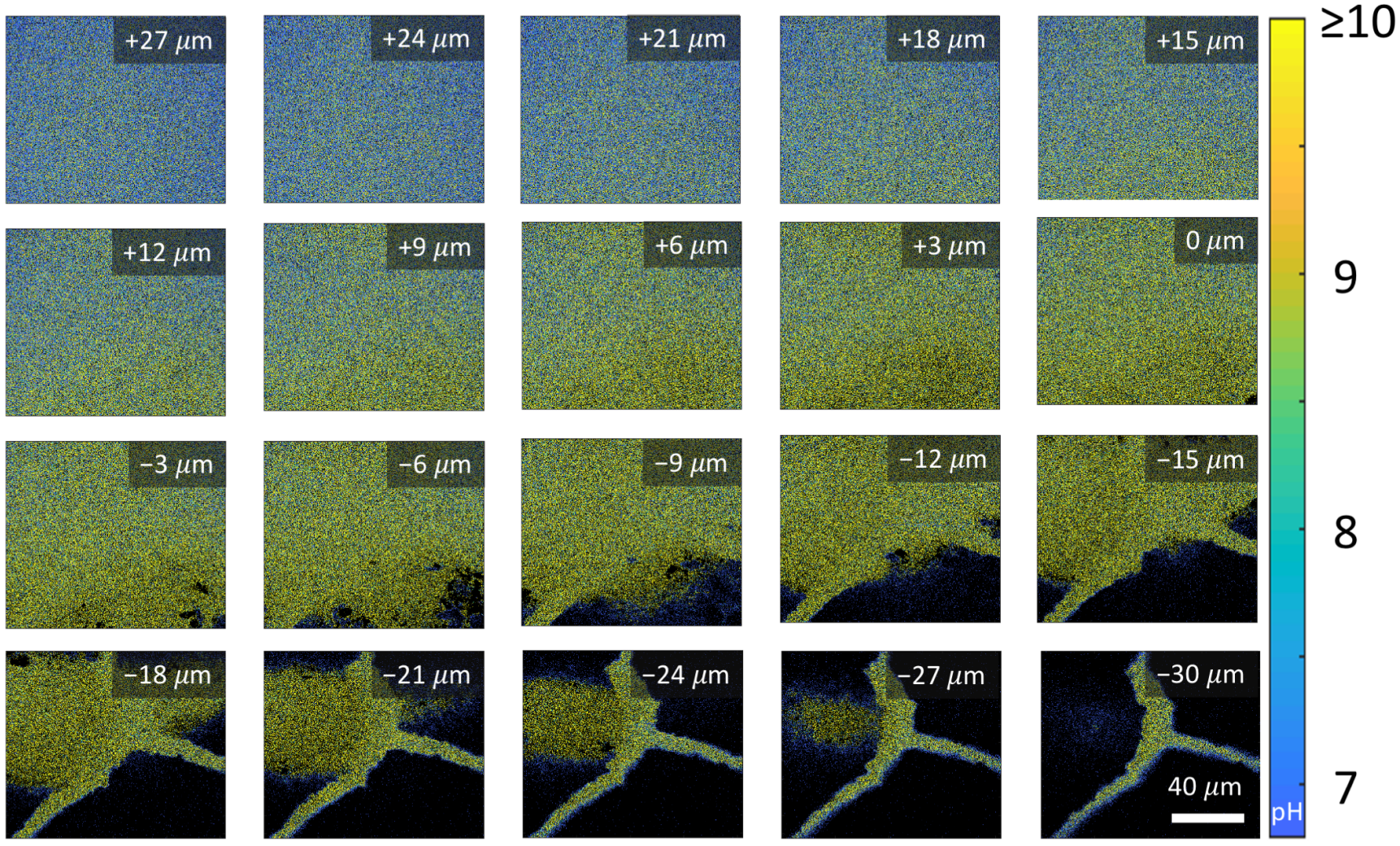

9

8

7

Figure S8: $\mathrm{pH}$ maps at the same location in $\mathrm{x}-\mathrm{y}$ on the electrode at different heights above the electrode surface at $-7.0 \mathrm{~mA} / \mathrm{cm}^{2}$. The map at the top left is at $30 \mu \mathrm{m}$ above the surface of the electrode. The map immediately to the right (top row second column from the left) is $27 \mu \mathrm{m}$ above the surface of the electrode. Each map is $3 \mu \mathrm{m}$ below the previous one starting from top left and moving to bottom right row by row. The bottom right map is $30 \mu \mathrm{m}$ below the electrode surface. The $\mathrm{pH}$ scale and scale bar at the right apply to all images. 

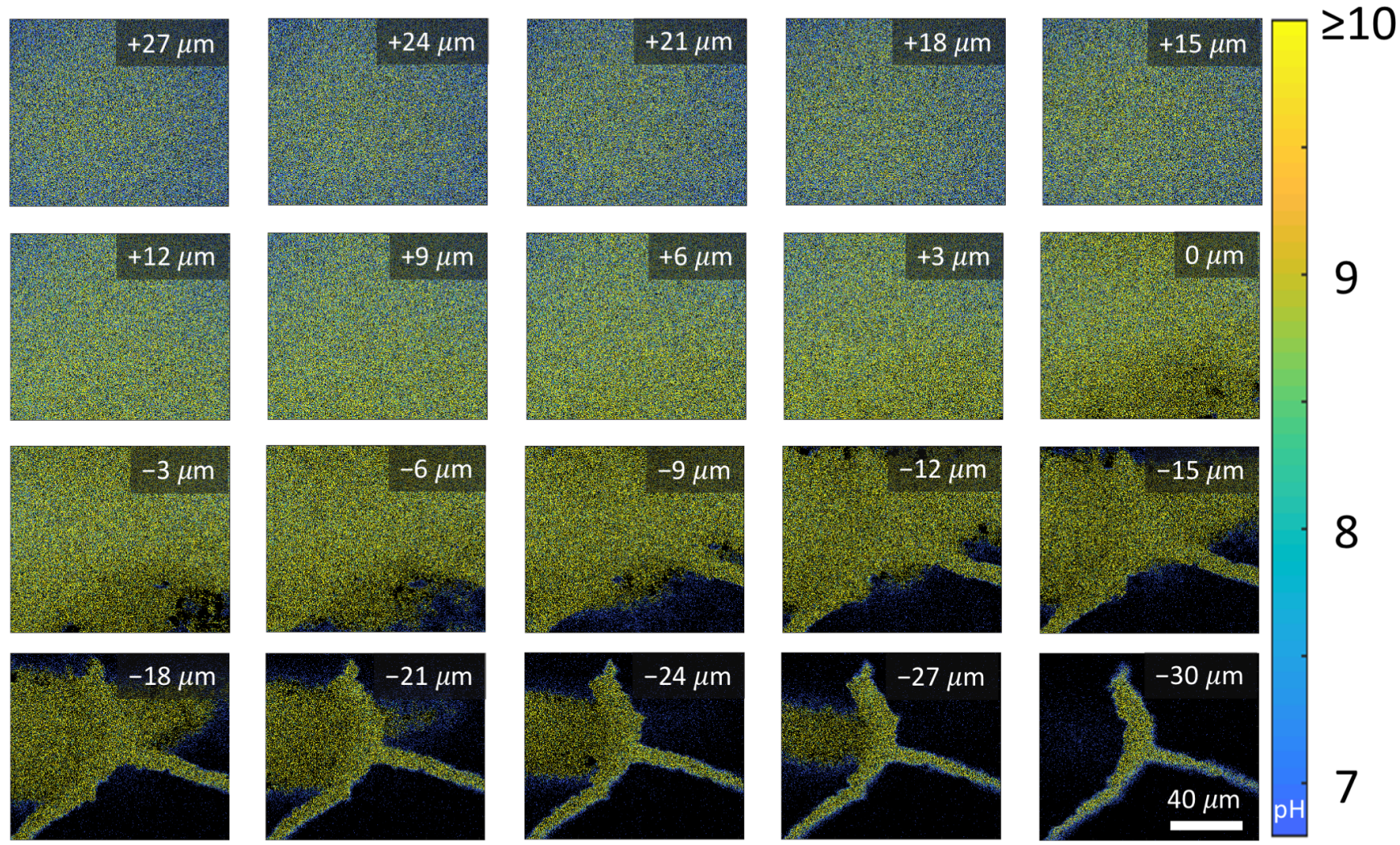

9

8

7

Figure S9: $\mathrm{pH}$ maps at the same location in $\mathrm{x}-\mathrm{y}$ on the electrode at different heights above the electrode surface at $-14.7 \mathrm{~mA} / \mathrm{cm}^{2}$. The map at the top left is at $30 \mu \mathrm{m}$ above the surface of the electrode. The map immediately to the right (top row second column from the left) is $27 \mu \mathrm{m}$ above the surface of the electrode. Each map is $3 \mu \mathrm{m}$ below the previous one starting from top left and moving to bottom right row by row. The bottom right map is $30 \mu \mathrm{m}$ below the electrode surface. The $\mathrm{pH}$ scale and scale bar at the right apply to all images. 

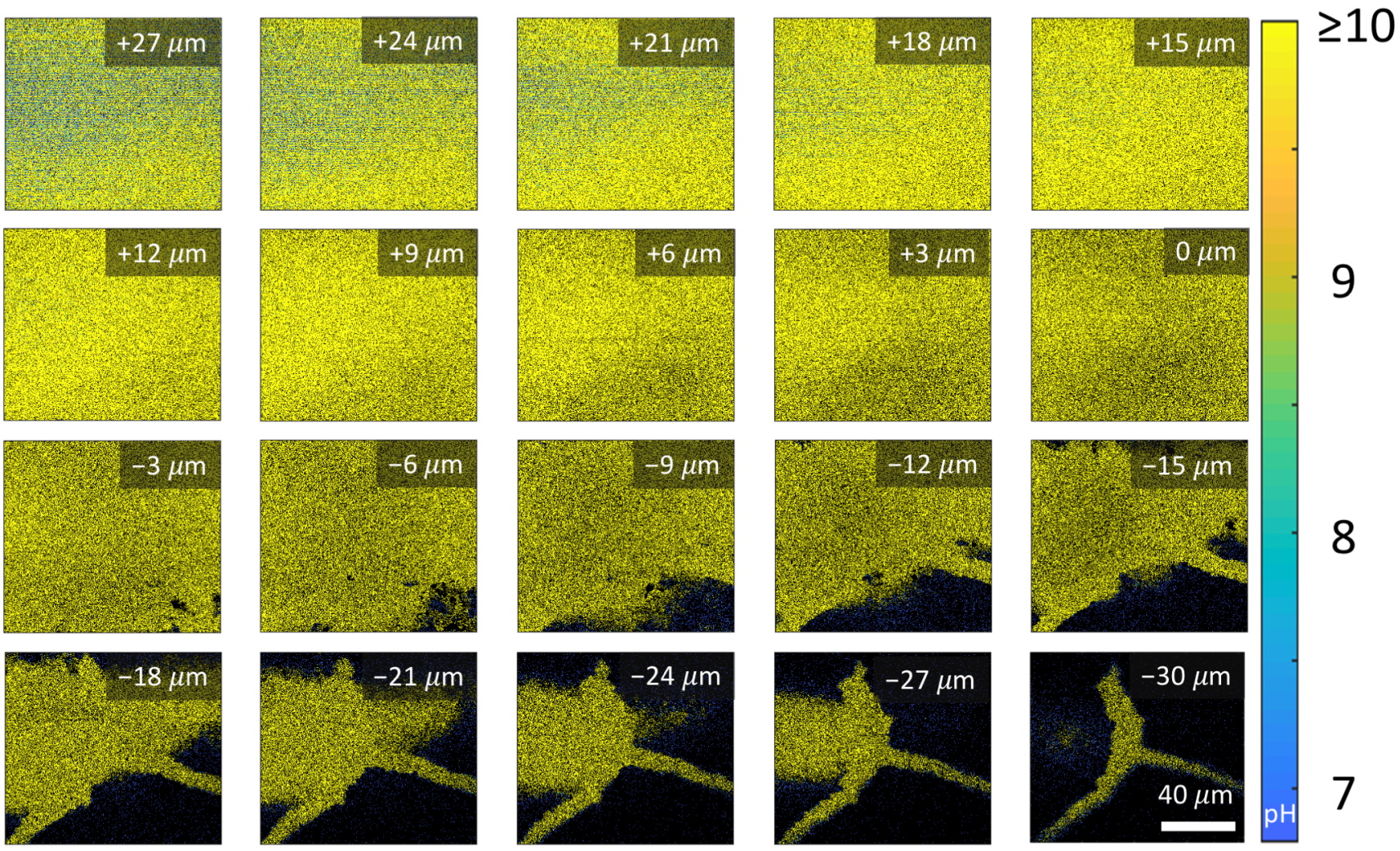

Figure S10: $\mathrm{pH}$ maps at the same location in $\mathrm{x}-\mathrm{y}$ on the electrode at different heights above the electrode surface at $-28.0 \mathrm{~mA} / \mathrm{cm}^{2}$. The map at the top left is at $30 \mu \mathrm{m}$ above the surface of the electrode. The map immediately to the right (top row second column from the left) is $27 \mu \mathrm{m}$ above the surface of the electrode. Each map is $3 \mu \mathrm{m}$ below the previous one starting from top left and moving to bottom right row by row. The bottom right map is $30 \mu \mathrm{m}$ below the electrode surface. The $\mathrm{pH}$ scale and scale bar at the right apply to all images. 

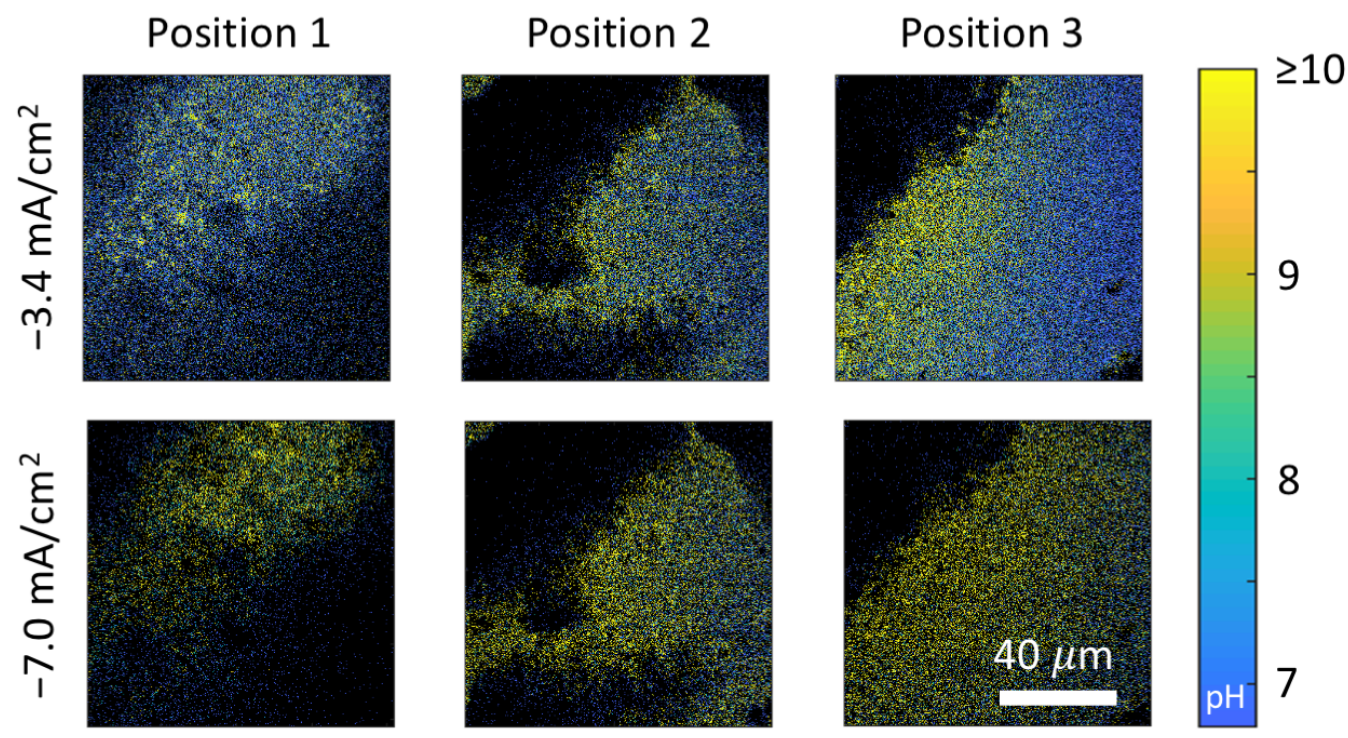

Figure S11: $\mathrm{pH}$ maps at three different locations along the electrode surface. Position 1 is off to the side of the electrolyte inlet, position 2 is near the electrolyte inlet, and position 3 is near the electrolyte outlet. The first row shows $\mathrm{pH}$ maps all taken at $-3.4 \mathrm{~mA} / \mathrm{cm}^{2}$ and the second row shows $\mathrm{pH}$ maps all taken at $7.0 \mathrm{~mA} / \mathrm{cm}^{2}$. We observe the hot spots for all 3 positions at $-3.4 \mathrm{~mA} / \mathrm{cm}^{2}$ and we do not observe the hot spots at $-7.0 \mathrm{~mA} / \mathrm{cm}^{2}$. 
a)

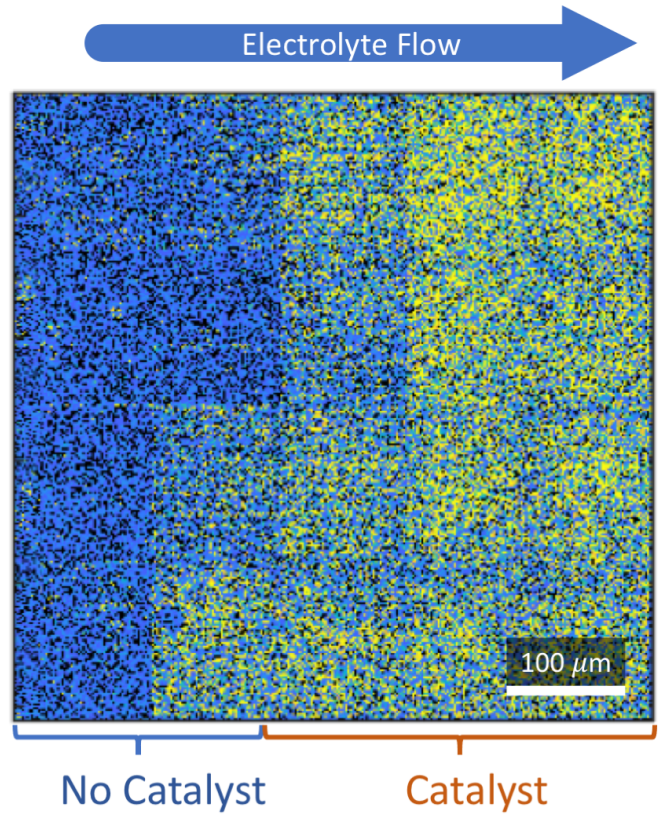

c)

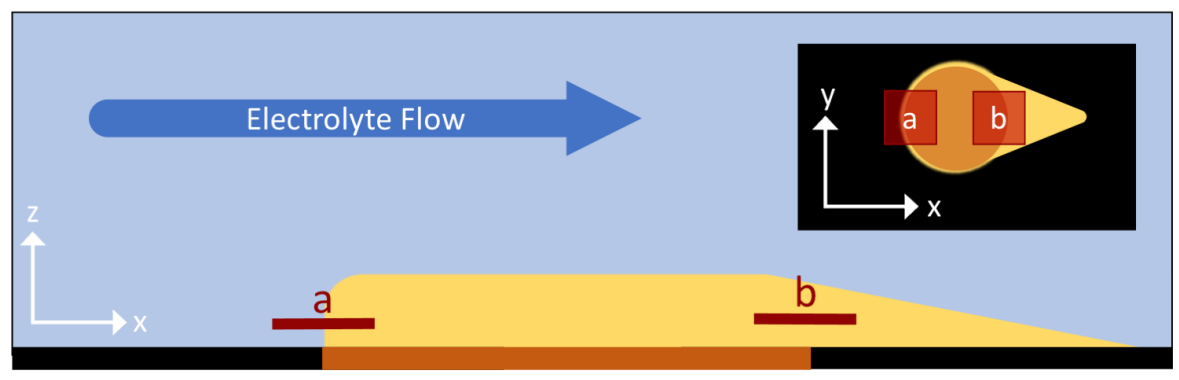

b)

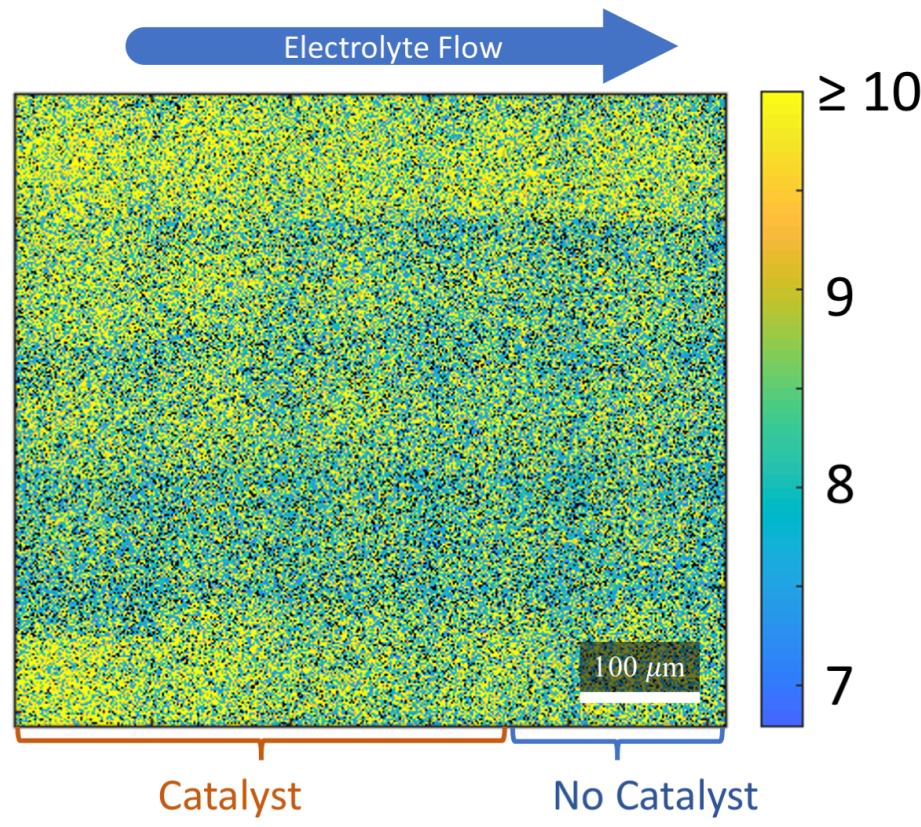

Area of increased $\mathrm{pH}$

GDE with catalyst

GDE with no catalyst

Bulk Electrolyte

Figure S12: Influence of electrolyte flow on the spatial resolution of $\mathrm{pH}$ maps. (a) and (b) are $\mathrm{pH}$ maps stitched together, taken at $9 \mu \mathrm{m}$ above the surface of the electrode and at a current density of -14.7 $\mathrm{mA} / \mathrm{cm}^{2}$. In (a) the left half of the image has no $\mathrm{Cu}$ while the right half has $\mathrm{Cu}$ catalyst. The electrolyte is flowing from left to right across the surface of the electrode. In (a) the left half of the image is coated with $\mathrm{Cu}$ while the right half has no $\mathrm{Cu}$ catalyst. The electrolyte is flowing from left to right across the surface. (c) shows a schematic that is not to scale of what the $\mathrm{pH}$ gradient looks like in both $\mathrm{x}-\mathrm{y}$ and $\mathrm{x}-\mathrm{z}$ planes. The area within the orange circle in the $\mathrm{x}-\mathrm{y}$ plane indicates where the $\mathrm{Cu}$ catalyst is located on the GDE. The position where image (a) was taken is indicated in panel (c) by the red square and the red line labeled ' $a$ '. The position where image (b) was taken is indicated in panel (c) by the red square and the red line labeled ' $b$ '. 

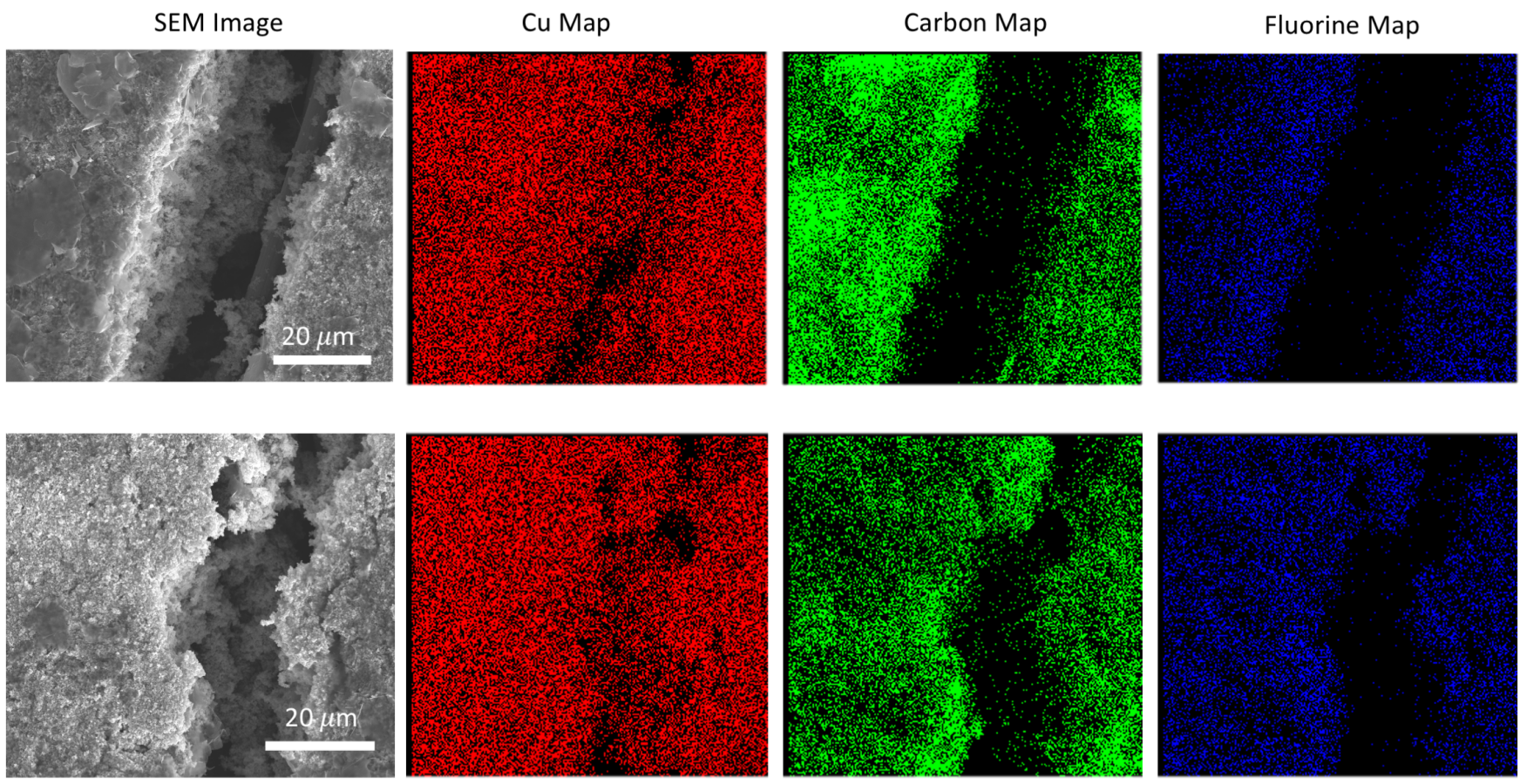

Figure S13: SEM and EDS maps of two locations on a GDE with $300 \mathrm{~nm} \mathrm{Cu}$. The SEM images at the left show the location for all EDS maps in the corresponding row. From the EDS maps we can see that at the bottom of the cracks, there is $\mathrm{Cu}$ while less carbon and PTFE (Fluorine signal) is present. 
a)

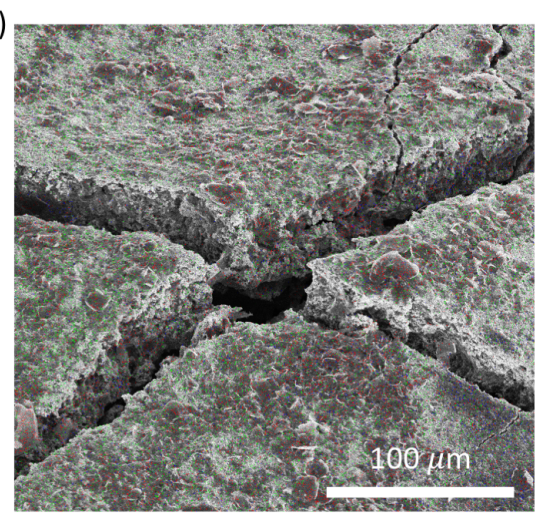

b)

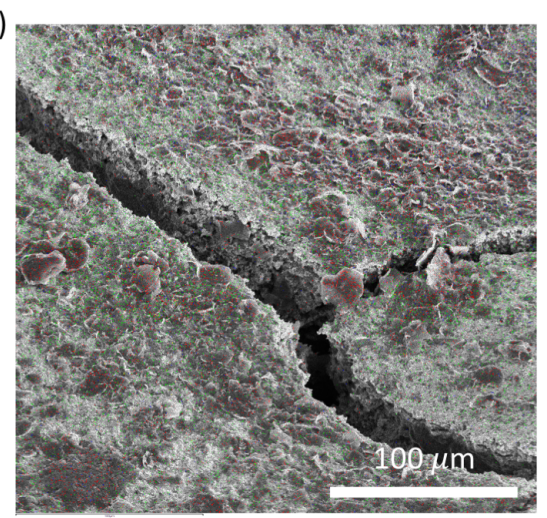

c)

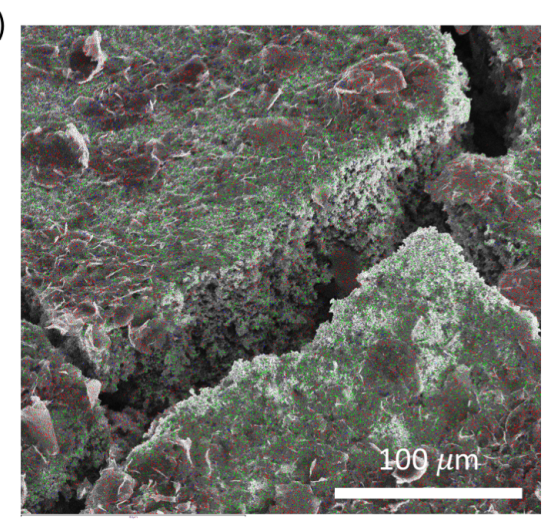

Figure S14: SEM and EDS maps of three locations on a GDE with $300 \mathrm{~nm} \mathrm{Cu}$. Red shading denotes carbon, green shading denotes $\mathrm{Cu}$, and blue indicates fluorine. From the EDS maps we can see that there is $\mathrm{Cu}$ deposited on the side walls of the trenches. 


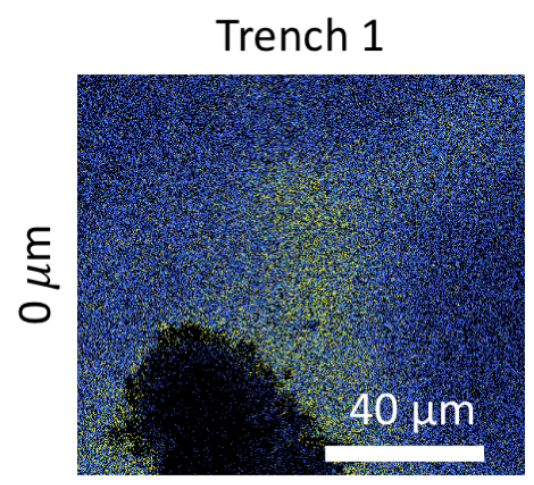

Trench 2
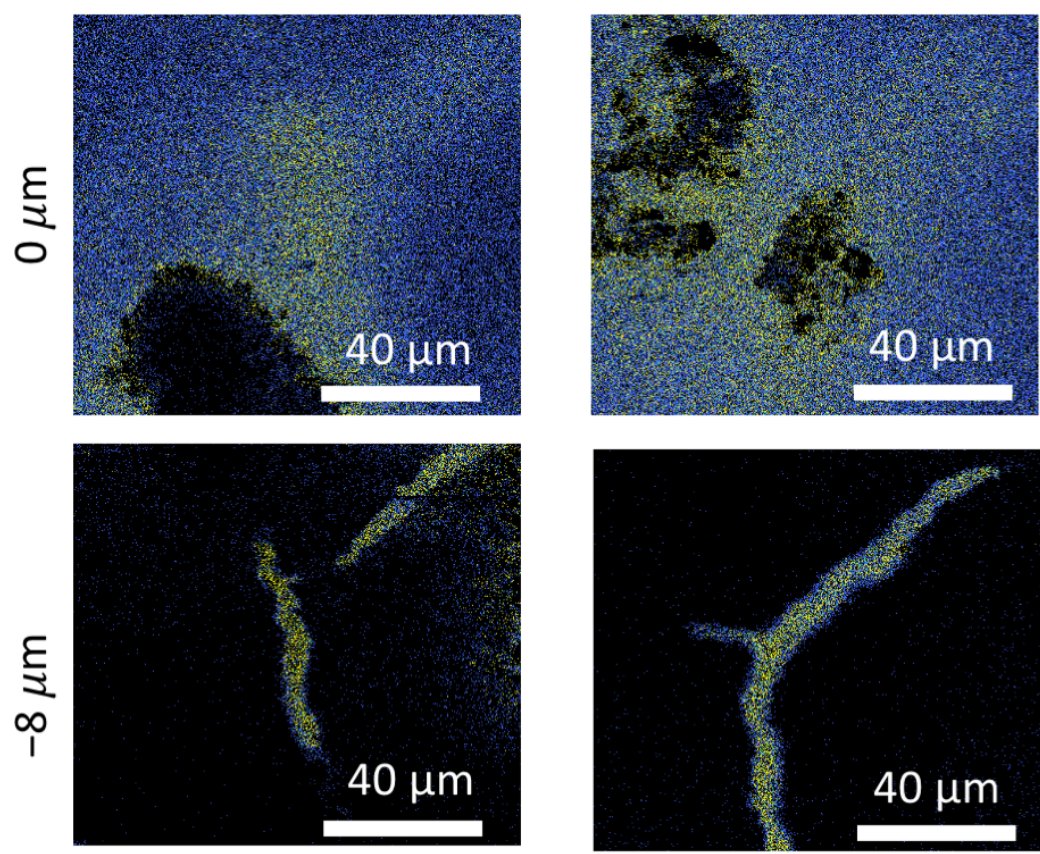

Trench 3
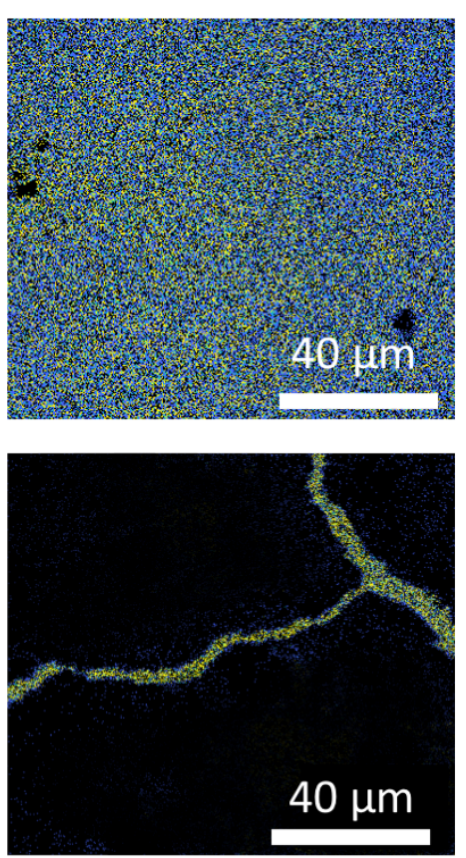

8

7

Figure S15: $\mathrm{pH}$ maps at three different locations along the electrode surface. All measurements were taken at $-3.4 \mathrm{~mA} / \mathrm{cm}^{2}$. The image in the first row is taken at the surface of the electrode and the second row is at $8 \mu \mathrm{m}$ below the surface $(0 \mu \mathrm{m})$. We observe that for all cases the $\mathrm{pH}$ within the narrow trench is higher than it is at the surface of the GDE. 

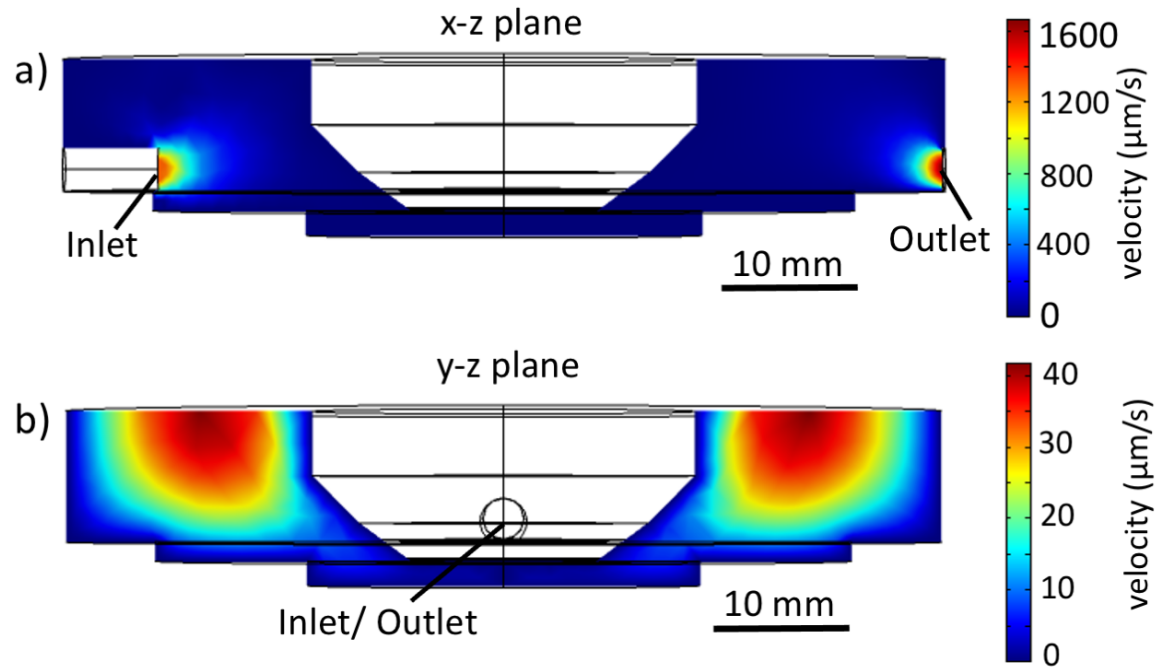

Figure S16: shows a COMSOL simulation of the velocity of the electrolyte in the electrochemical cell with the objective submerged in the electrolyte. (a) shows the velocity in the $x-z$ plane with the inlet on the left and outlet on the right. (b) shows the velocity in the $y$-z plane with the electrolyte flowing into the page. From these simulations it is clear that the velocity underneath the objective is small. 
a)

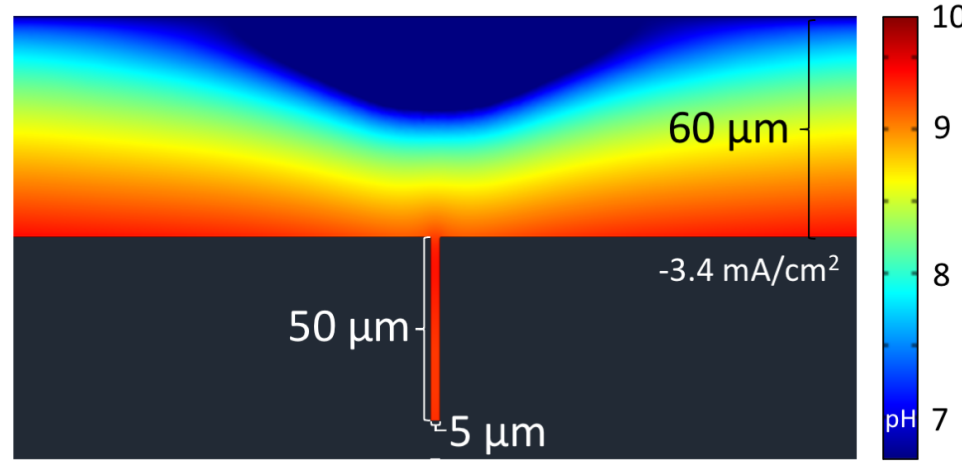

b)

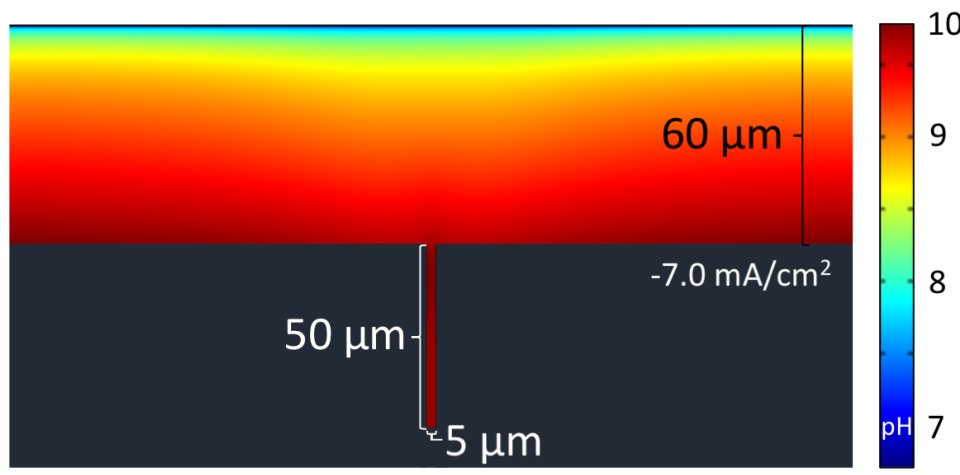

c)

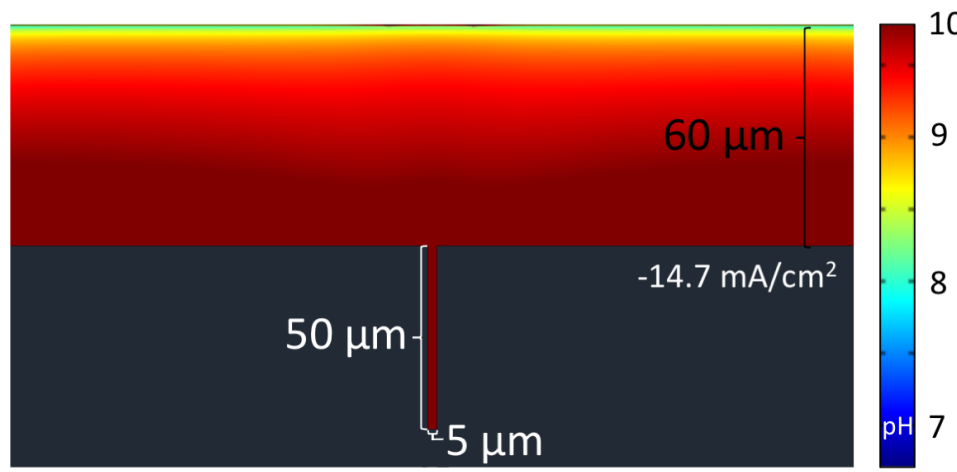

Figure S17: shows COMSOL simulations of the $\mathrm{pH}$ profile in a trench that is $5 \mu \mathrm{m}$ wide and $50 \mu \mathrm{m}$ deep at different current densities. The current density is constant over all surfaces. (a) shows the $\mathrm{pH}$ profile at $-3.4 \mathrm{~mA} / \mathrm{cm}^{2}$, (b) shows the $\mathrm{pH}$ profile at $-7.0 \mathrm{~mA} / \mathrm{cm}^{2}$, and (c) shows the $\mathrm{pH}$ profile at -14.7 $\mathrm{mA} / \mathrm{cm}^{2}$. From these simulations we observe that the $\mathrm{pH}$ near the catalyst layer increases as the current density increases. 